Universidade de Brasília - UnB

Faculdade de Economia, Administração, Contabilidade e Ciência da Informação e Documentação - FACE

DANIELA DE LIMA SOYER

DILEMAS E POSSIBILIDADES PARA A TRANSFORMAÇÃO DO PLANO DE CAPACITAÇÃO ANUAL DOS TÉCNICOS ADMINISTRATIVOS EM EDUCAÇÃO DA UNIVERSIDADE DE BRASÍLIA, COM ÊNFASE NA FORMAÇÃO STRICTO SENSU PROFISSIONAL 
DANIELA DE LIMA SOYER

DILEMAS E POSSIBILIDADES PARA A TRANSFORMAÇÃO DO PLANO DE CAPACITAÇÃO ANUAL DOS TÉCNICOS ADMINISTRATIVOS EM EDUCAÇÃO DA UNIVERSIDADE DE BRASÍLIA, COM ÊNFASE NA FORMAÇÃO STRICTO SENSU PROFISSIONAL

Monografia apresentada no curso de Gestão Universitária do Programa de Pós-Graduação em Administração da Faculdade de Economia, Administração, Contabilidade e Ciência da Informação e Documentação - FACE, da Universidade de Brasília, como requisito parcial para obtenção do grau de Especialista em Gestão Universitária.

Orientadora: Professora Doutora Marisa Cardoso Trindade

Brasília - DF

Junho de 2010 


\section{TÍTULO: DILEMAS E POSSIBILIDADES PARA A TRANSFORMAÇÃO DO PLANO DE CAPACITAÇÃO ANUAL DOS TÉCNICOS ADMINISTRATIVOS EM EDUCAÇÃO DA UNIVERSIDADE DE BRASÍLIA, COM ÊNFASE NA FORMAÇÃO STRICTO SENSU PROFISSIONAL}

Monografia apresentada no curso de Gestão Universitária do Programa de Pós-Graduação em Administração da Faculdade de Economia, Administração, Contabilidade e Ciência da Informação e Documentação - FACE, da Universidade de Brasília, como requisito parcial para obtenção do grau de Especialista em Gestão Universitária.

Professora Doutora Marisa Cardoso Trindade

Banca Examinadora:

Professora Doutora Marisa Cardoso Trindade (ORIENTADORA)

Professor Doutor César Augusto Tibúrcio Silva (MEMBRO) 
Dedico o presente trabalho aos meus pais, pela dedicada educação oferecida a mim, aos colegas do CESPE/UnB e da FACE, que me apoiaram para a conclusão deste curso, e à minha filha Marina, pelo sentido dado à minha vida diariamente. 
"Produzir, integrar e divulgar conhecimento, formando cidadãos comprometidos com a ética, a responsabilidade social e o desenvolvimento sustentável."

Missão da Universidade de Brasília 


\section{RESUMO}

O presente trabalho apresenta as dificuldades e os desafios dos ocupantes ativos do cargo de técnico administrativo em educação da Universidade de Brasília, interessados no ingresso à formação stricto sensu, especificamente no curso de mestrado profissionalizante oferecidos pela UnB. Hoje, para o referido grupo de servidores, não há disponibilidade de inserção em cursos de mestrados profissionalizantes promovidos pela UnB como parte do plano de capacitação anual, chegando à conclusão de que a Universidade poderia absorver esse contingente, a ponto de qualificar pessoas do próprio quadro, necessitando para isso de mudanças nas diretrizes traçadas para o referido plano, objetivando a elevação do nível de qualificação de seus servidores e resultando assim no melhor atendimento à comunidade, nos processos envolvidos e na satisfação dos beneficiados.

Palavras-chave: Dificuldades. Técnicos administrativos em educação. Demanda. Ingresso. Universidade de Brasília. Mestrado profissionalizante. Qualificação. Reformulação. Satisfação. 


\section{LISTA DE GRÁFICOS}

Gráfico 1 - Qual a sua idade?

Gráfico 2 - Qual o seu grau de instrução?

Gráfico 3 - Você tem interesse em cursar algum mestrado profissionalizante oferecido pela Universidade de Brasília. 26

Gráfico 4 - Você já cursou algum mestrado profissionalizante que não tenha sido oferecido pela Universidade de Brasília? 27

Gráfico 5- Enumere abaixo por ordem de prioridade de 1 a 4 , sendo 1 maior prioridade e 4 menor prioridade, o objetivo do seu interesse para a inserção em cursos stricto sensu (profissionalizante). 28

Gráfico 6 - Houve alguma tentativa ou interesse de sua parte para se inscrever em algum mestrado profissionalizante na UnB que não foi bem-sucedida?

Gráfico 7 - Caso você tenha sinalizado algum motivo na questão n. 6, indique abaixo o que você pretende fazer em relação ao mestrado profissionalizante. 


\section{SUMÁRIO}

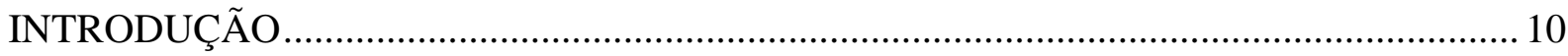

2 REAL SITUAÇÃO FUNCIONAL DOS TÉCNICOS ADMINISTRATIVOS EM

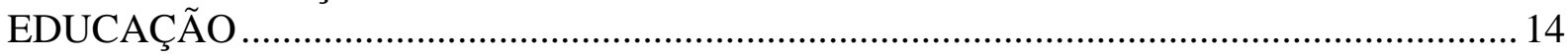

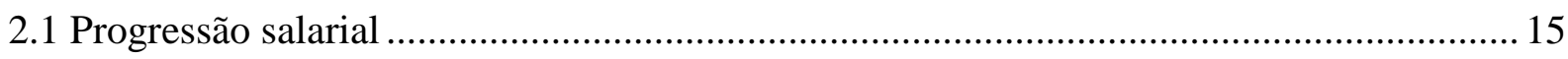

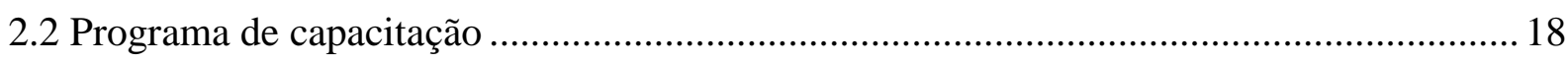

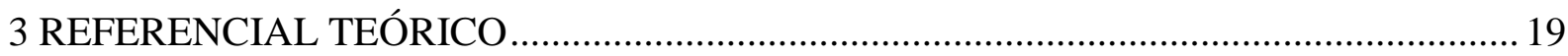

3.1 Relevância da formação para os Empregados ....................................................................... 20

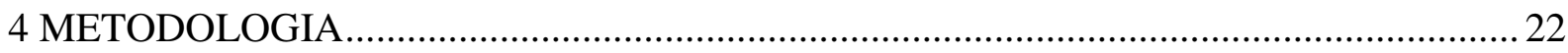

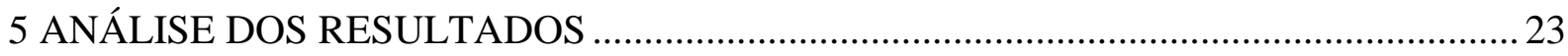

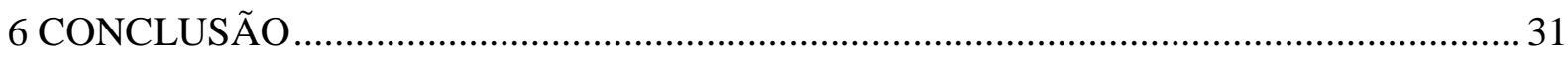

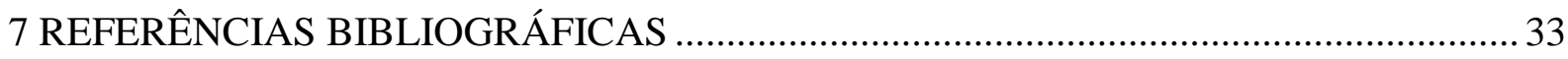

Apêndice - Questionário aplicado aos Técnicos Administrativos em Educação da

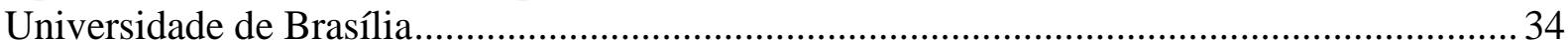

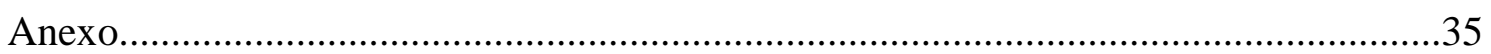




\section{INTRODUÇÃO}

A Universidade de Brasília (UnB) foi inaugurada em 21 de abril de 1962 por sua mantenedora, a Fundação Universidade de Brasília - que foi instituída nos termos da Lei n. 3.998 em 15 de dezembro de 1961 -, é possuidora, atualmente, de uma estrutura composta, hierarquicamente e com relativa autonomia, pelas seguintes unidades: 1 Assessoria, 29 Centros, 5 Decanatos, 60 Departamentos, 25 Faculdades e Institutos, 1 Hospital Veterinário, Prefeitura, Reitoria, 6 Secretarias, 5 campi - Plano Piloto (o Darcy Ribeiro), Ceilândia, Gama e Planaltina, além dos núcleos de extensão de São Sebastião e Brazlândia, e 5 órgãos complementares, que auxiliam os alunos no desenvolvimento de trabalho de ensino, pesquisa e extensão. São eles: o Hospital Universitário de Brasília, a Biblioteca Central, a Fazenda Água Limpa, a UnB TV e a Editora UnB.

Em todo o ambiente acima relatado, estão distribuídos cerca de 2.700 servidores públicos da ativa, sendo mais de 1.900 docentes e cerca de 800 técnicos administrativos em educação, sem contar os cerca de 2.000 prestadores de serviços, que também colaboram diariamente pelo exercício dos três pilares que dão suporte à Universidade: o ensino, a pesquisa e a extensão.

Este trabalho apresenta as possibilidades e as dificuldades encontradas pelos técnicos administrativos em educação da UnB interessados no ingresso à formação stricto sensu, em que aqui será tratado especificamente o mestrado profissionalizante, considerando sua estrutura, seu custo e sua acessibilidade. Chegando à conclusão de que a Universidade poderia absorver esse contingente, a ponto de qualificar pessoas do próprio quadro, necessitando para isso de mudanças nas diretrizes traçadas para o plano de capacitação anual dos seus servidores, objetivando a elevação do nível de 
qualificação deles e resultando assim no melhor atendimento à comunidade, nos processos envolvidos e na satisfação dos beneficiados.

Salienta-se, ainda, que o serviço público vem exigindo cada vez mais das pessoas uma postura voltada ao autodesenvolvimento e à aprendizagem contínua. Investir em capacitação do servidor é um desafio que o País tem.

A realidade dos servidores públicos, no que tange à sua formação, é diferenciada dependendo de sua função, o que pode não surpreender ninguém, considerando que os níveis existem também com o intuito de distinguir a capacidade intelectual de cada profissional, o que incentiva aqueles que estão em um nível menor a adquirir certificação para progredirem funcionalmente.

Os docentes e técnicos administrativos em educação, por exemplo, se diferenciam consideravelmente: ao primeiro é exigido o pré-requisito da certificação mínima proporcionada na conclusão da formação stricto sensu, enquanto os técnicos administrativos em educação são divididos em vários níveis de formação (do fundamental ao superior), visto que exercem funções diferenciadas. Entretanto, mesmo em se tratando de funções que, teoricamente, exigem níveis diferentes de esforço mental, nada impede a ascensão intelectual desses técnicos, considerando que, uma vez mais bem qualificados, consequentemente, melhor será o serviço dispensado à comunidade pela Universidade.

Desta forma, a questão-problema deste estudo é: Quais as dificuldades e os desafios dos ocupantes ativos do cargo de técnico administrativo da Universidade de Brasília, interessados no ingresso à formação stricto sensu, especificamente no curso de mestrado profissionalizante oferecidos pela UnB? 
Partindo da questão-problema, entende-se como primordial a necessidade de identificar os desafios e as dificuldades dos ocupantes ativos do cargo de técnico administrativo da UnB, interessados na formação stricto sensu, especificamente nos cursos de mestrado profissionalizante oferecidos pela UnB.

No decorrer da pesquisa, tornou-se necessária também a identificação da demanda interessada em mestrados profissionalizantes entre os técnicos administrativos em educação da Universidade e do seu perfil, de forma a conceituar essa demanda e os meios de inserção, contribuindo assim para a criação de programa interno de seleção no ingresso à formação stricto sensu (mestrado profissionalizante), para o bem-estar da demanda beneficiada e para a valorização do servidor por meio de mérito. Salientando o crescimento intelectual individual do servidor gerado nesse processo.

Atualmente, a Faculdade de Economia, Administração, Contabilidade e Ciências da Informação e Documentação - FACE da UnB promove a sexta turma, sem custo para o aluno, na inserção do curso de especialização voltado para gerentes (servidores e prestadores de serviços) da UnB portadores de curso superior em qualquer área do conhecimento, que proporciona a aquisição e o aprofundamento de conhecimentos, o desenvolvimento de habilidades, a mudança de atitudes, a melhoria da capacidade de elaboração científica e de utilização de uma mentalidade gerencial crítica e renovada.

Entretanto, essa é uma iniciativa verticalmente singular, por não existir um programa de formação continuada, de forma pontual, voltado especificamente para os servidores da Universidade, e, o que torna anda mais pertinente, a promoção da referida formação pela própria UnB. 
Trata-se de uma demanda reprimida quando existente. A formação stricto sensu na UnB por parte do seu corpo funcional, hoje, é possível da forma convencional, o que leva esse contingente interessado a ser mais um candidato entre os demais (externos à comunidade).

Deve-se salientar ainda que muitos dos servidores da Universidade, no momento da escolha da instituição de ensino que proporcionará o alcance da conclusão da formação stricto sensu, buscam a certificação fora do Brasil (por exemplo, a cidade de Assunção, no Paraguai), onde é possível o fácil acesso com o custo menor, considerando que em Brasília-DF, e no Brasil, em geral, o acesso é caro e concorrido. Sendo que, para efeito de alcance de nível no Plano de Carreira da UnB, a certificação de vários cursos concluídos pelos servidores fora do Brasil pode ser legal e válida.

Depara-se então com um conflito. Internamente e pontualmente não existe o aproveitamento dos profissionais, servidores públicos, interessados em uma formação stricto sensu profissionalizante. Formação esta que proporciona ao servidor uma estrutura compatível à necessidade aqui apresentada, incentiva o crescimento profissional e intelectual do corpo funcional, além da satisfação pessoal em alcançar um certificado na instituição onde trabalha. E isso, sem dúvida, cria um forte laço afetivo entre o profissional e a instituição. Em contrapartida, fora do País ou em outras instituições brasileiras, esses servidores alcançam a certificação pretendida, que, muitas vezes, é legalmente aceita, para a elevação de nível na carreira na Universidade. 


\section{REAL SITUAÇÃO FUNCIONAL DOS TÉCNICOS ADMINISTRATIVOS EM EDUCAÇÃO}

A visão apresentada neste trabalho, apesar de pioneiro, não é alcançada apenas pelo respectivo autor. Cabe destacar que hoje há uma força tarefa composta por servidores que resistiram a preconceitos, já que, há uns 20 anos, eles eram vistos apenas como meros executores de atividades operacionais. Na época, quando se tratava de capacitação, eram beneficiados apenas com treinamentos para o aperfeiçoamento dessas atividades burocráticas. Esses profissionais enfrentaram diversos obstáculos no que tange a seu crescimento intelectual e profissional na instituição de ensino onde trabalham. Existem alguns raros casos de servidores que chegaram ao mestrado, ao doutorado e ao pós-doutorado por iniciativa própria e não por incentivo da Universidade.

E outros que ainda não alcançaram a referida meta e ainda buscam esse crescimento. Assim, eles se reúnem diariamente, discutem na tentativa de encontrar possíveis caminhos para o alcance da conclusão do mestrado profissionalizante.

A título de exemplo, essa demanda interessada foi exposta em reunião com o responsável da Universidade Metropolitana de Assunção, em maio de 2010, convidado por interessados a expor as possibilidades que a referida instituição pode oferecer na conclusão do mestrado profissionalizante, desde o reconhecimento do certificado oferecido junto à UnB até os custos e as condições para a conclusão.

Nesse encontro, foi detectada a necessidade de o aluno residente no Brasil ter de se deslocar até Assunção duas vezes ao ano, além das aulas presenciais realizadas no Brasil no decorrer de dois anos, que é a duração do curso, mediante pagamento da 
mensalidade no valor de $\mathrm{R} \$ 600,00$ no decorrer de 24 meses e a inscrição de $\mathrm{R} \$ 300,00$, sendo que para o ingresso não é necessário participar de seleção, basta fazer a inscrição.

Iniciativas como essa deixam claro o interesse único e exclusivo do servidor em relação à progressão salarial, considerando o desconhecimento e a falta de confiança junto a instituições procuradas quando é solicitada a garantia da habilitação à progressão salarial e não somente ao exercício da docência. Percebe-se, também, a falta de incentivo da Universidade, o que não deve ser visto como um desmerecimento de alguma possibilidade de qualificação beneficiada pela Universidade de Brasília, considerando que o crescimento intelectual desses servidores será oferecido também à própria UnB.

\subsection{Progressão salarial}

Hoje o servidor público da Universidade de Brasília vive um contexto de dúvidas quanto ao pagamento da Unidade de Referência de Preços (URP), valor esse que esteve incorporado em seus salários durante tanto tempo. Para muitos, essa perda serve de motivação para o alcance da titulação do mestrado, considerando que o percentual recebido pela URP representa o mesmo quantitativo recebido pela titulação, objeto desse estudo.

É válido salientar que, conforme regras estabelecidas pela Secretaria de Recursos Humanos da Universidade de Brasília em parceria com o Programa de Treinamento e Capacitação Funcional (PROCAP), são citadas no sítio da UnB “o incentivo à qualificação - além da progressão profissional, o plano de carreira do servidor técnico administrativo oferece um incentivo ao servidor que possui educação 
formal excedente ao requisito do cargo de que é titular. O benefício é pago em percentuais, fixados na tabela abaixo, podendo variar de $5 \%$ a $75 \%$. O incentivo pode ser recebido após quatro anos de efetivo exercício no cargo e é calculado sobre o padrão do vencimento do servidor".

Observe a seguir na tabela de percentuais de incentivo à qualificação publicada pela SRH da Universidade. 
Tabela de percentuais de incentivo à qualificação

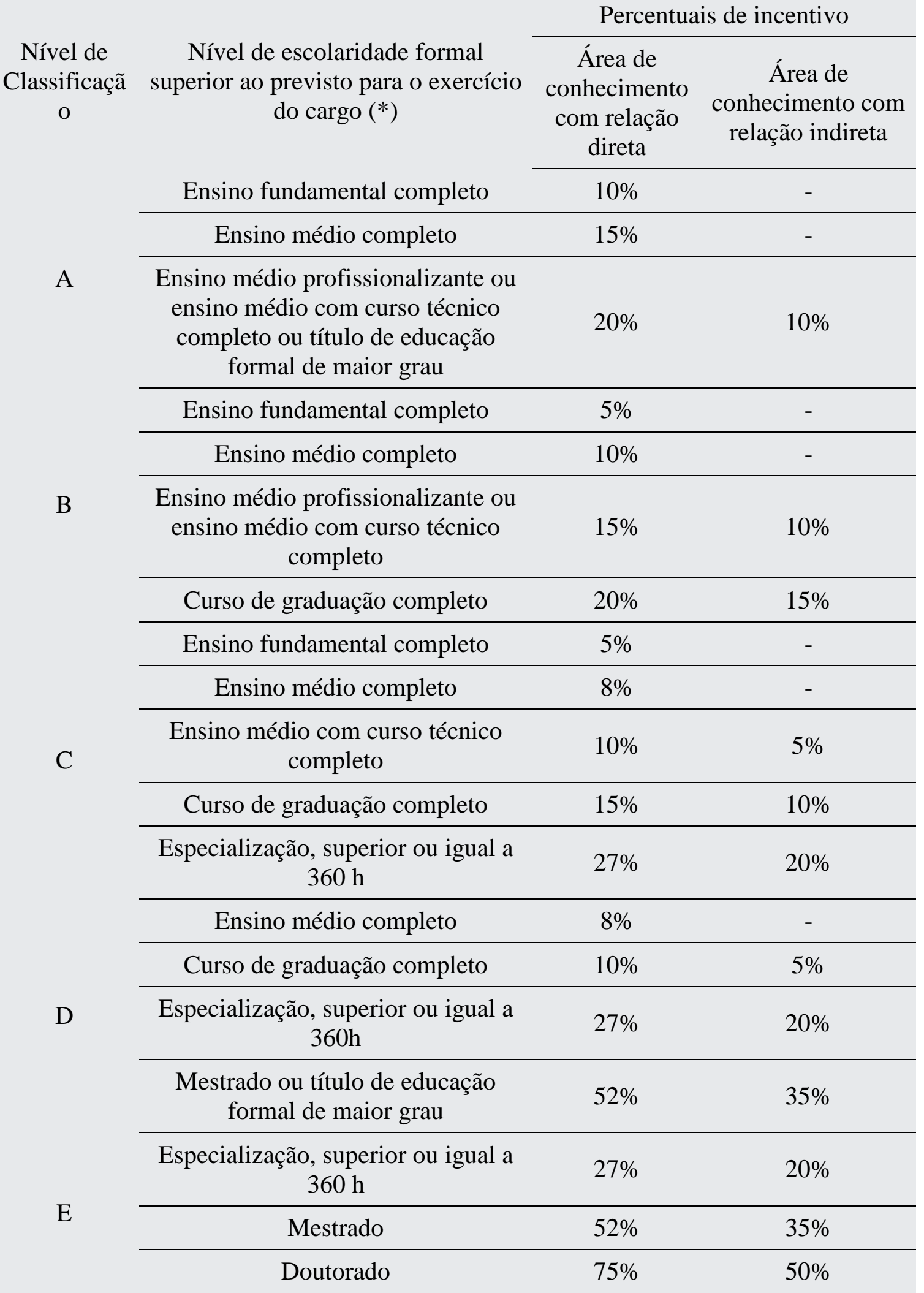

(*) Curso reconhecido pelo Ministério da Educação

Fonte: Redação dada pelo Decreto n ${ }^{\circ} 5.824$, de 2006. 


\subsection{Programa de Capacitação}

As diretrizes para a elaboração do Plano de Desenvolvimento dos Integrantes do Plano de Carreira dos Cargos Técnicos Administrativos em Educação da Universidade de Brasília (PDIC/UnB) - instituídas pela Lei $\mathrm{n}^{\circ}$ 11.091/2005, pelo Decreto $n^{\circ} 5.707 / 2006$, pelo Decreto $n^{\circ} 5.824 / 2006$ e pela Resolução do Conselho de Administração da UnB no 003/2002 - têm como objetivo geral atualizar e reformular o Programa de Capacitação, segundo as orientações da legislação atual e em acordo com as necessidades da Instituição e dos seus colaboradores.

Institucionalmente, o PDIC/UnB entende o Desenvolvimento Humano como a função e o processo pelos quais é possível transformar o potencial das pessoas e das equipes de trabalho em competências e interesse em atingir resultados previamente definidos e negociados pela gestão da Universidade.

O referido Plano contempla diversas informações que convergem com o presente estudo. Entretanto, na prática, observa-se a carência de uma política de Recursos Humanos mais bem estruturada, sistematizada, considerando, por exemplo, a comunicação entre a Secretaria de Recursos Humanos (SRH) e os servidores que por muitas vezes desconhecem os benefícios oferecidos. Observa-se então que o Plano, instituído em dezembro de 2006, não foi implantado em sua totalidade pela UnB devido a algumas deficiências da Universidade, como espaço físico precário, falta de pessoal e recursos financeiros insuficientes, entre outros. 


\section{REFERENCIAL TEÓRICO}

Este capítulo contém uma análise da produção científica sobre os temas relacionados no processo de implementação de um programa de capacitação: a avaliação de desempenho dos servidores, conforme o primeiro item disposto abaixo. Em seguida, apresenta os métodos de avaliação para seleção e colocação, bem como a evolução e a qualidade dos cursos de pós-graduação oferecidos pela UnB.

Antigamente, os cursos de formação eram vistos pelas empresas como um custo e sem retorno. Hoje, as empresas investem em cursos de formação, pois necessitam de funcionários que estejam muito bem preparados para enfrentar desafios que possam surgir no futuro. Segundo Paul Spector (2003), o aperfeiçoamento dos sistemas de avaliação de desempenho representa um importante desafio dentro da psicologia organizacional, considerando que as medidas objetivas frequentemente são deficientes por não apresentarem adequadamente toda a abordagem do desempenho das pessoas no trabalho. Para os trabalhos como o proposto aqui, cujo resultado é definido e que pode ser quantificado, o desenvolvimento de critério pode ser relativamente fácil e direto.

Uma das primeiras aplicações da psicologia no campo dos problemas humanos, dentro das organizações, foi, segundo Spector (2003), a avaliação de pessoas para seleção e colocação. Durante a Primeira Guerra Mundial, foi realizado o primeiro teste em larga escala para determinar as funções (ou colocações) das pessoas no exército dos Estados Unidos. Após a guerra, as empresas de grande porte perceberam o valor potencial da avaliação de candidatos a emprego pelo processo de seleção e outras formas de decisão, tornando comum o uso de testes e técnicas. Hoje, esse aspecto é verdadeiro na maioria dos países do mundo industrializado, incluindo o Canadá, a Europa Ocidental e Israel. 


\subsection{Relevância da formação para os Empregados}

$\mathrm{O}$ atual momento em que milhares de trabalhadores brasileiros tentam manter o emprego, aceitando até a redução da jornada de trabalho e dos salários, os servidores públicos federais alcançam melhores condições de trabalho. O governo Lula incluiu, entre os 325 artigos da Medida Provisória nº 441 (BRASIL 2008b), reajuste salarial para parte das carreiras, bem como mudanças no Regime Jurídico Único do funcionalismo, acrescentando mais uma vantagem para a categoria. Agora, qualquer servidor poderá se licenciar para fazer mestrado (até dois anos) ou doutorado (até quatro anos), no País ou no exterior, recebendo o salário integral, inclusive as férias e o $13^{\circ}$ salário.

Antes, a Lei n 8.112/91 (BRASIL, 1991) previa apenas afastamento para "participação em programa de treinamento regularmente instituído, conforme dispusesse o regulamento". Somente alguns órgãos disciplinaram a inclusão de cursos de pós-graduação stricto sensu (que titulam o estudante como mestre e doutor em determinado campo do conhecimento) nas possibilidades de licença do serviço com recebimento de salário. Boa parte das carreiras não contemplava essa licença remunerada, mas apenas licença remunerada para participação em conferências, seminários, congressos e treinamentos.

Mesmo nos órgãos que permitiam a licença para pós-graduação, o servidor recebia salário menor, porque era descontada a gratificação por desempenho no exercício da função.

Como as MPs $n^{\circ} 440 / 08$ e $n^{\circ} 441 / 08$, foi instituído o vencimento de várias categorias por meio de subsídio, em parcela única, incorporando a gratificação por 
desempenho. O servidor nessa condição sai agora para estudar recebendo o salário integral, caso dos auditores-fiscais e integrantes da carreira jurídica.

As novas regras estão em vigor desde agosto do ano passado, quando a MP, que ainda tramita no Congresso, foi editada. Conforme o artigo 96-A, o afastamento acontecerá desde que a realização do mestrado ou doutorado "não possa ocorrer simultaneamente com o exercício do cargo ou mediante compensação de horário".

A Lei $n^{\circ} 8.112 / 91$ já permite que os servidores se licenciem do cargo por até três anos, para assuntos particulares (o que inclui até trabalho na iniciativa privada), sem remuneração, tendo a garantia do emprego na volta, com o mesmo salário ou até maior, caso haja reajuste para a carreira durante o período da ausência.

Válido como tempo de serviço, o governo também garantiu, na MP nº 441, que a licença para mestrado ou doutorado contará como tempo de serviço para aposentadoria. A alteração na lei dá condição para que isso ocorra até mesmo nos casos em que o servidor opte por se afastar sem remuneração, quando o curso não for de interesse do órgão.

Para ser remunerado, o mestrado ou o doutorado escolhido deve ser submetido à aprovação dos chefes e ser do interesse do órgão. Após três anos no serviço público, incluído o estágio probatório de dois anos, o servidor já poderá se licenciar para fazer o mestrado. No caso do doutorado, são quatro anos. 


\section{METODOLOGIA}

Foi feita uma pesquisa quantitativa e aplicada, que segundo Ander-Egg (1978), caracteriza-se por seu interesse prático, isto é, que os resultados sejam aplicados ou utilizados, imediatamente, na solução de problemas que ocorrem na realidade. Uma vez com o resultado compilado, no âmbito da amostragem, que é o número de técnicos que compartilham com as mesmas características, pode-se saber quem tem o interesse no ingresso à formação stricto sensu, especificamente no curso de mestrado profissionalizante.

Entre os cerca de 830 técnicos administrativos atualmente ocupantes do cargo na ativa da UnB, estava prevista a aplicação do questionário para $10 \%$ desse público. Entretanto, a greve atingiu a maioria das unidades a serem visitadas, o que tornou impraticável o alcance da referida meta. Dessa forma, o questionário foi aplicado para 51 técnicos administrativos lotados nas unidades da Reitoria, da Faculdade de Economia, Administração, Contabilidade e Ciência da Informação e Documentação FACE, e do Centro de Seleção e de Promoção de Eventos da Universidade de Brasília CESPE/UnB.

O instrumento utilizado para a realização de entrevistas foi um questionário composto por questões objetivas e discursivas (fechadas e abertas), a fim de atingir o perfil dos interessados ou não à formação stricto sensu (mestrado profissionalizante) dentre os ocupantes ativos do cargo de técnicos administrativos da Universidade, que consta do Apêndice do presente trabalho.

O referido questionário foi aplicado pessoalmente pelo pesquisador ou enviados e recebidos por email, individualmente, no período de março a abril de 2010 , de forma que o entrevistado não teve a obrigatoriedade de se identificar. 


\section{ANÁLISE DOS RESULTADOS}

Seguem os enunciados das questões que compuseram o questionário deste presente estudo com a respectiva projeção de dois gráficos e comentário para cada questão.

Questão 1: Qual a sua idade?

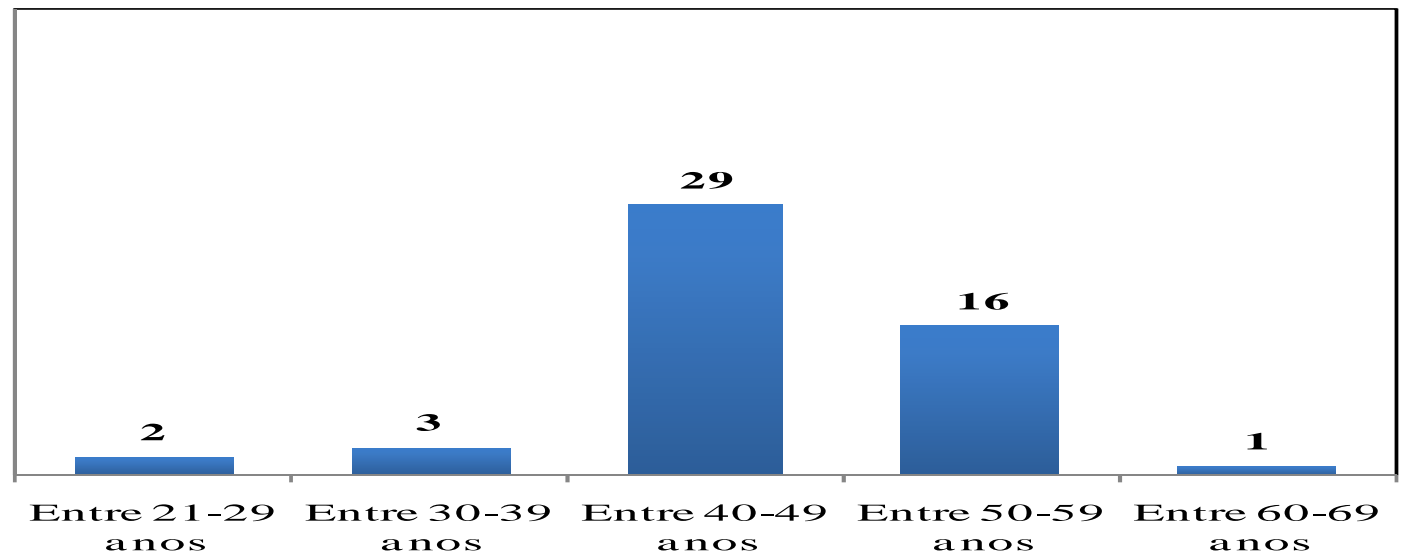

Percentual

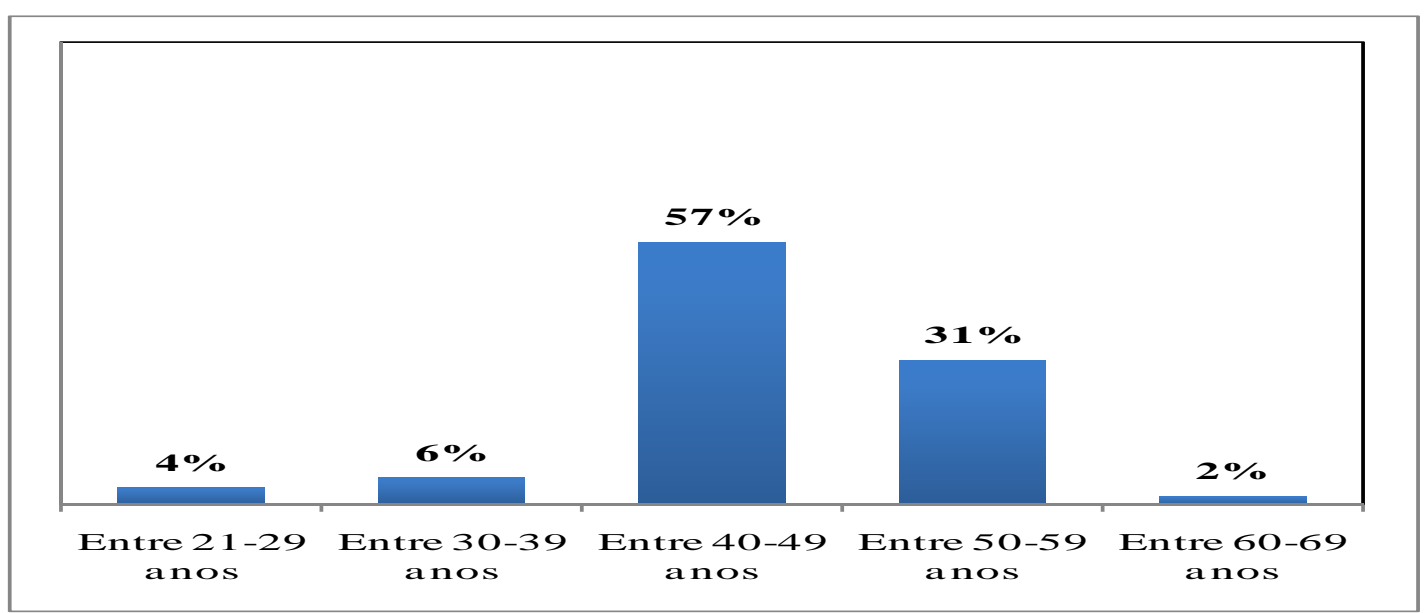

Comentário:

Percebe-se pelos gráficos que $57 \%$ dos 51 entrevistados, ou seja, 29 entrevistados, estão na faixa etária entre os 40 a 49 anos, o que representa a maioria em uma faixa etária intermediária. Ficando em segundo lugar de maior recorrência a faixa entre os 50 e 59 anos. 
Questão 2: Qual o seu grau de instrução?

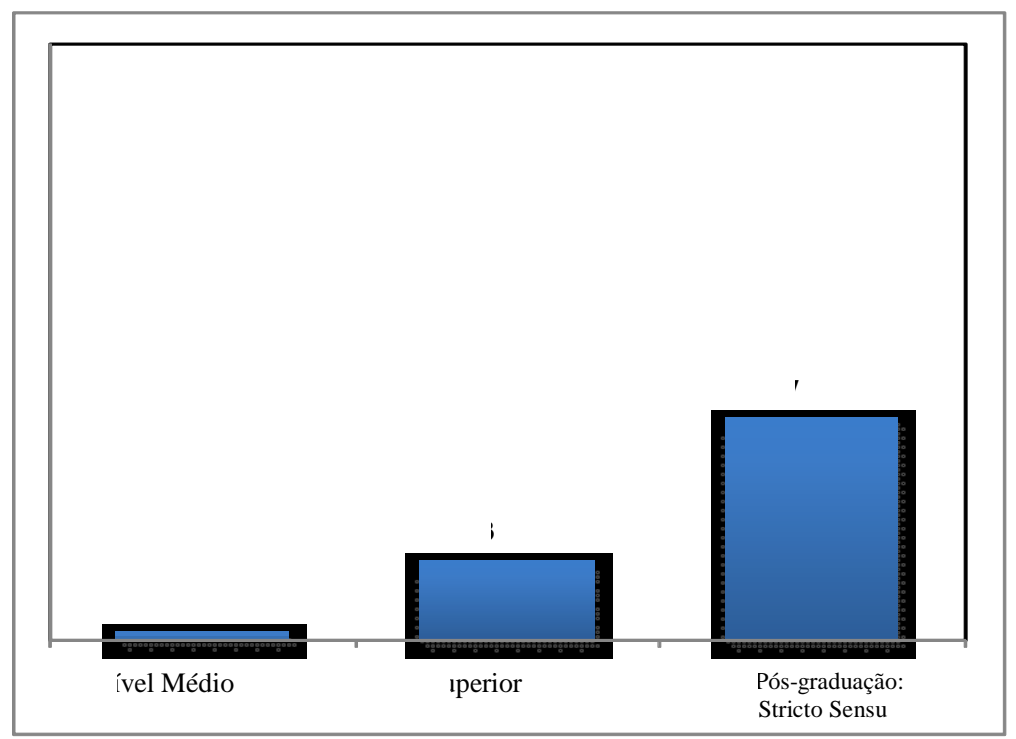

\section{Percentual}

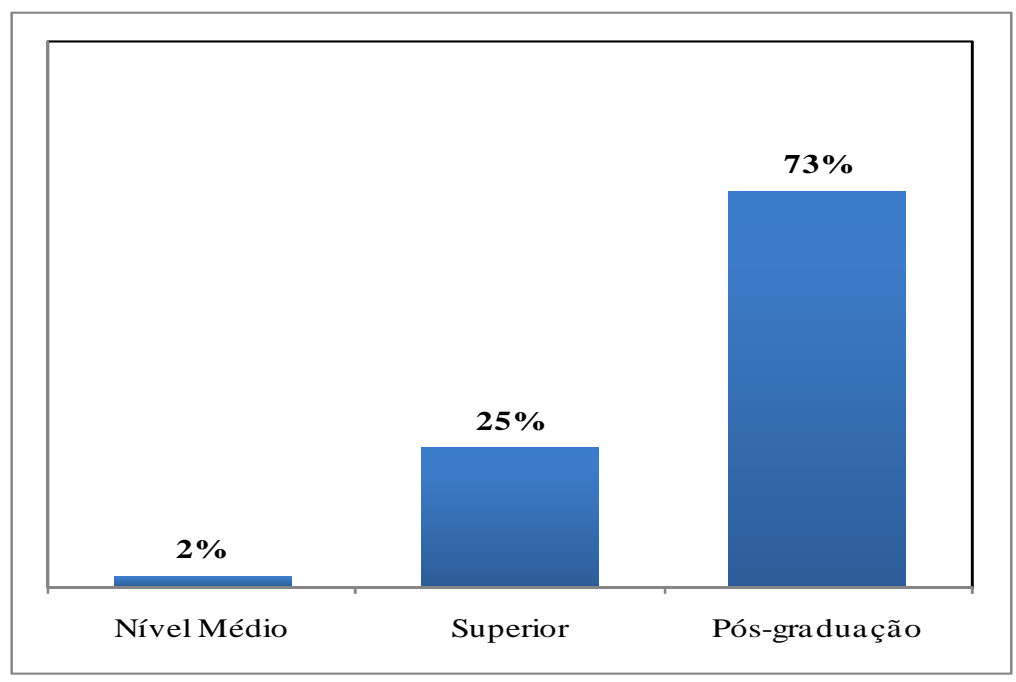

Comentário:

Entre os entrevistados, $73 \%$ já concluíram alguma especialização, enquanto $13 \%$ deles já concluíram o curso superior. E somente um, até o momento, concluiu apenas o nível médio. 
Questão 3: Você tem interesse em cursar algum mestrado profissionalizante oferecido pela Universidade de Brasília?

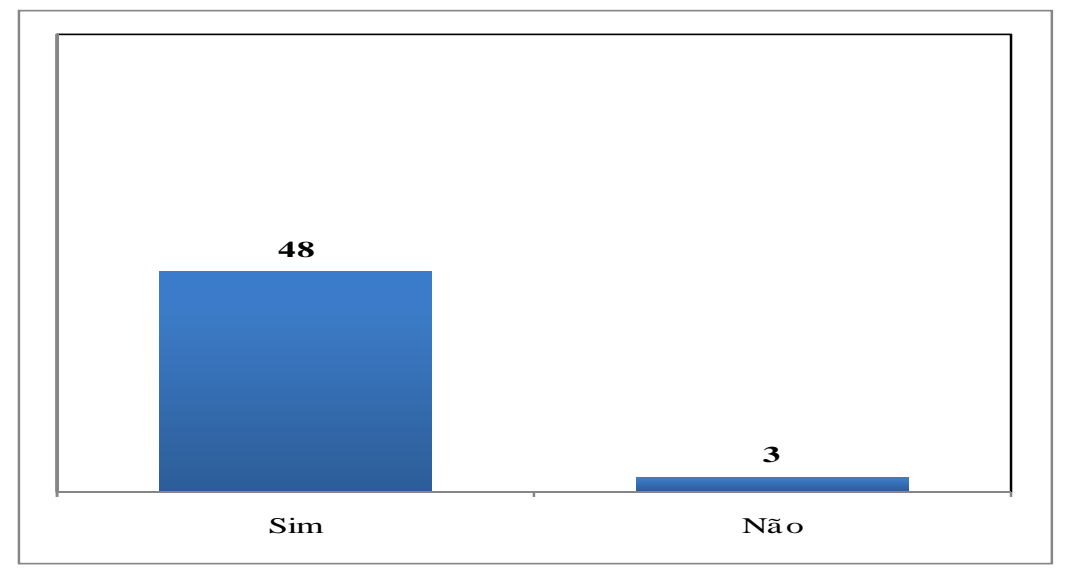

\section{Percentual}

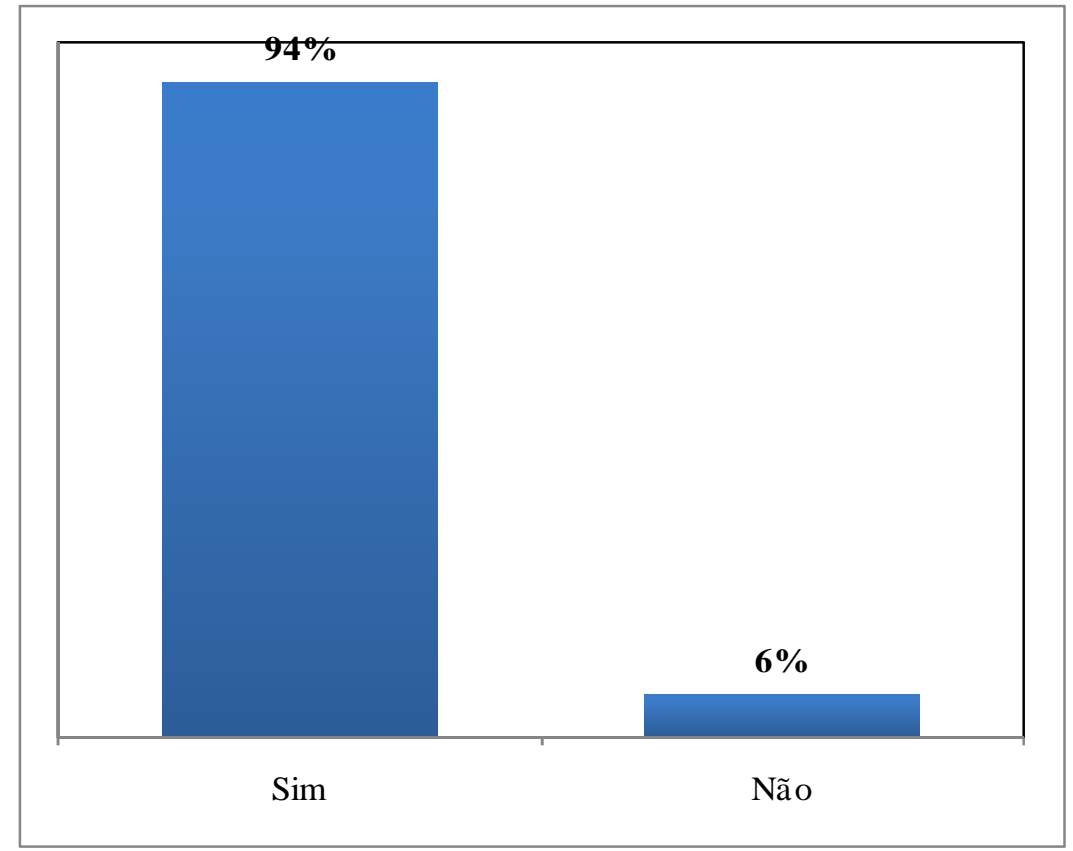

Comentário:

É possível verificar a alta demanda interessada em cursar mestrado profissionalizante oferecido pela Universidade de Brasília, considerando o percentual identificado de $94 \%$ de interessados. 
Questão 4: Você já cursou algum mestrado profissionalizante que não tenha sido oferecido pela Universidade de Brasília?

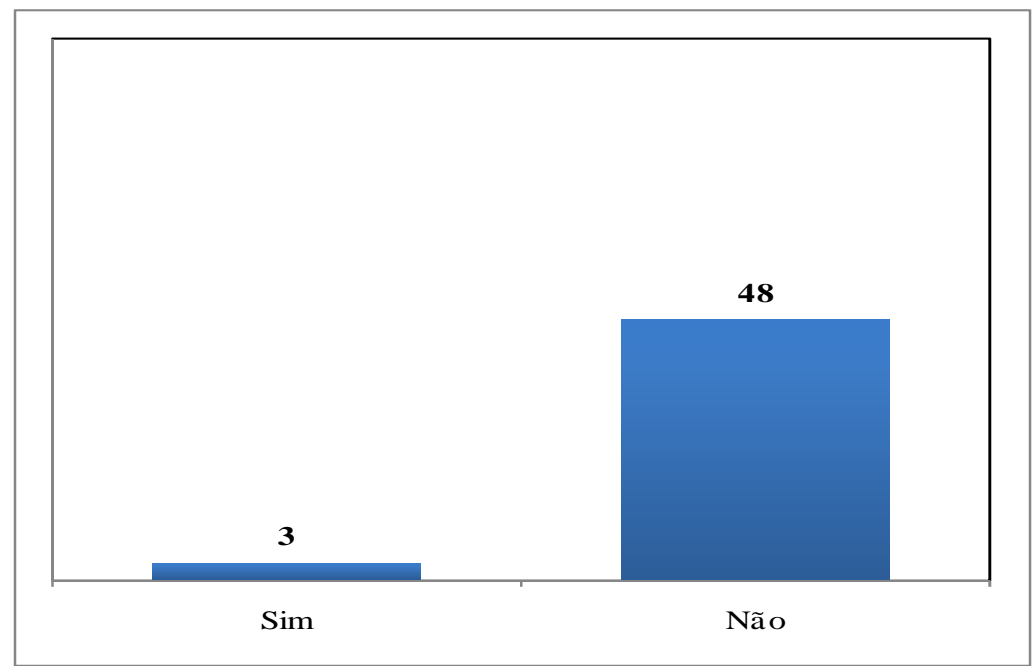

Percentual

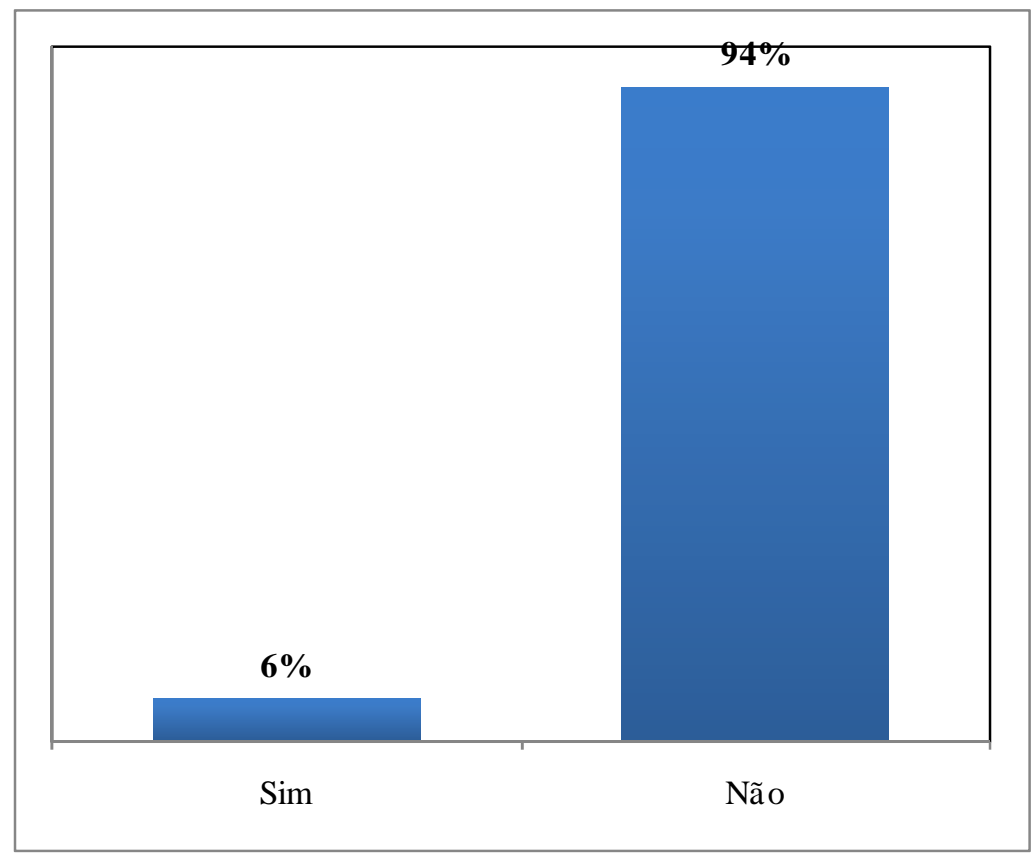

Comentário:

Vê-se que poucos são aqueles, entre os entrevistados, que já cursaram algum curso de mestrado profissionalizante que não tenha sido oferecido pela UnB. Entre os 51 entrevistados, somente 3 alcançaram a referida titulação fora da Universidade. O que reflete a alta demanda de futuros alunos em cursos de mestrados profissionalizantes. 
Questão 5: Enumere abaixo por ordem de prioridade de 1 a 4, sendo 1 maior prioridade e 4 menor prioridade, o objetivo do seu interesse para a inserção em cursos stricto sensu (mestrado profissionalizante)

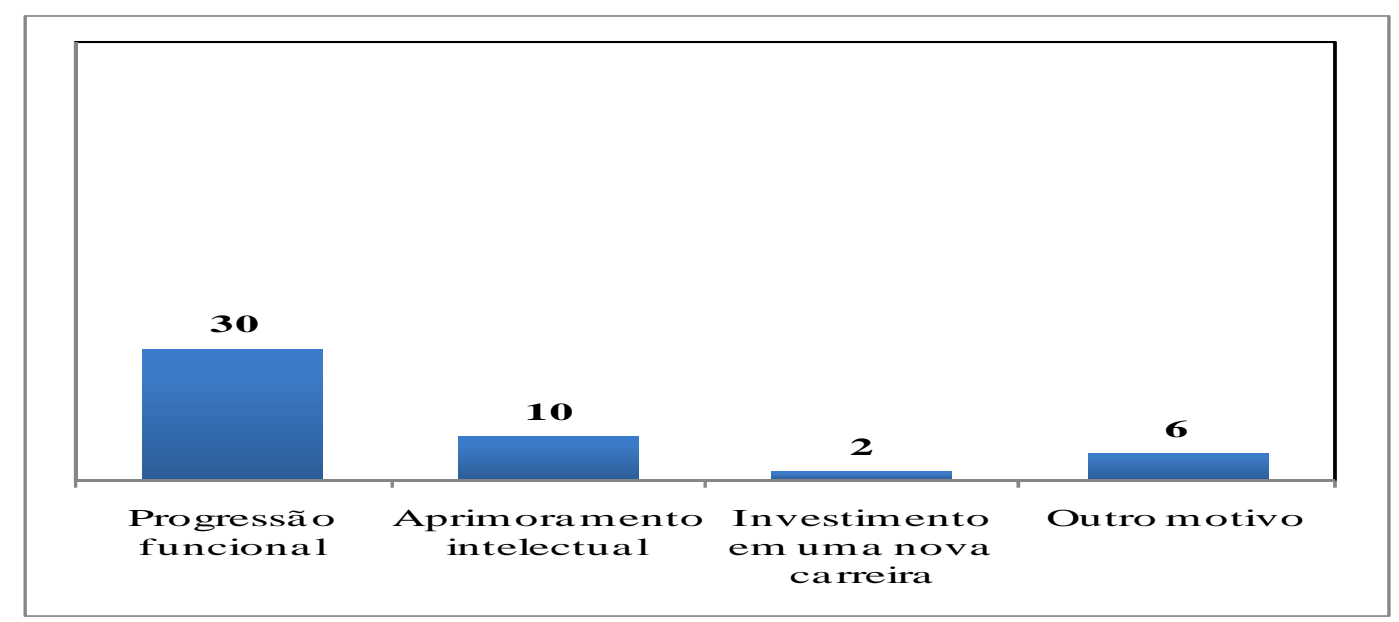

Percentual

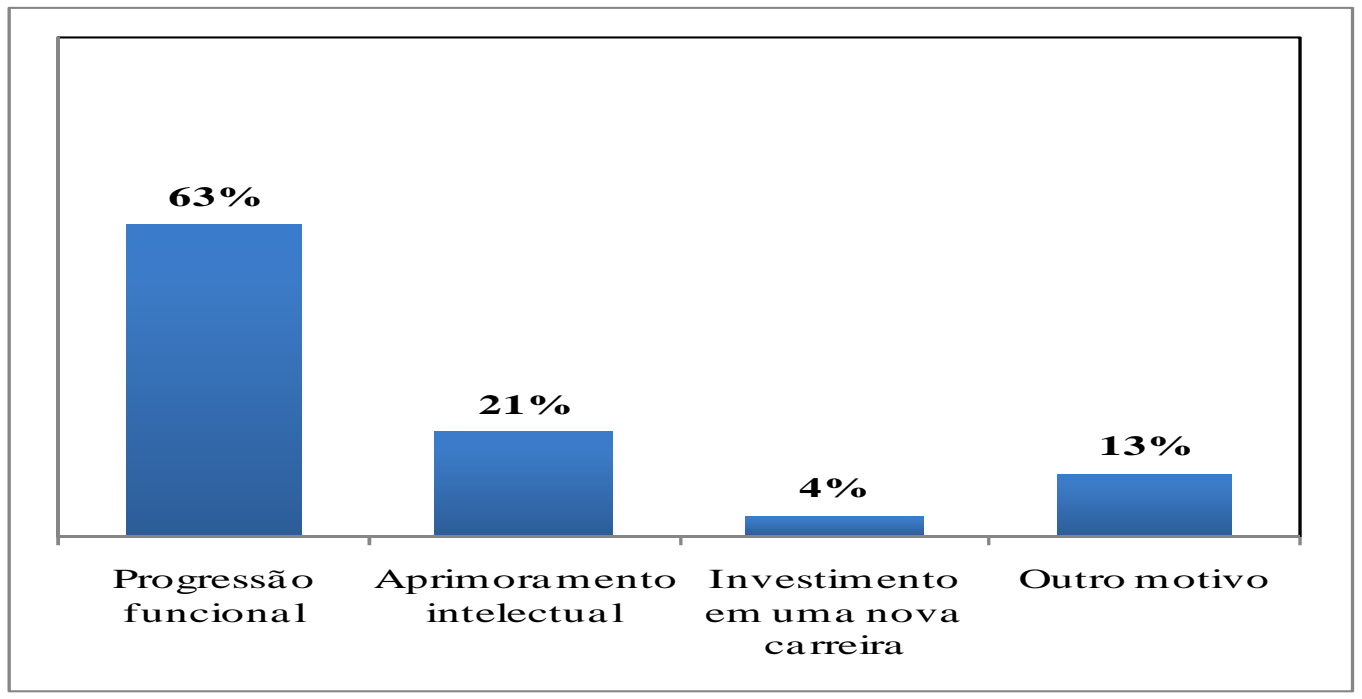

Comentário:

Entre os entrevistados, $63 \%$ elegeram a progressão funcional como prioridade na inserção em mestrado profissionalizante; 21\%, o aprimoramento intelectual; $13 \%$, outro motivo e $4 \%$, o investimento em uma nova carreira, o que reflete a necessidade monetária da maioria, considerando o estágio da vida funcional que se encontra. Muitos aguardam apenas a referida certificação para requerer a aposentadoria. 
Questão 6: Houve alguma tentativa ou interesse de sua parte para se inscrever em algum mestrado profissionalizante na UnB que não foi bem-sucedida? ( ) sim ( ) não
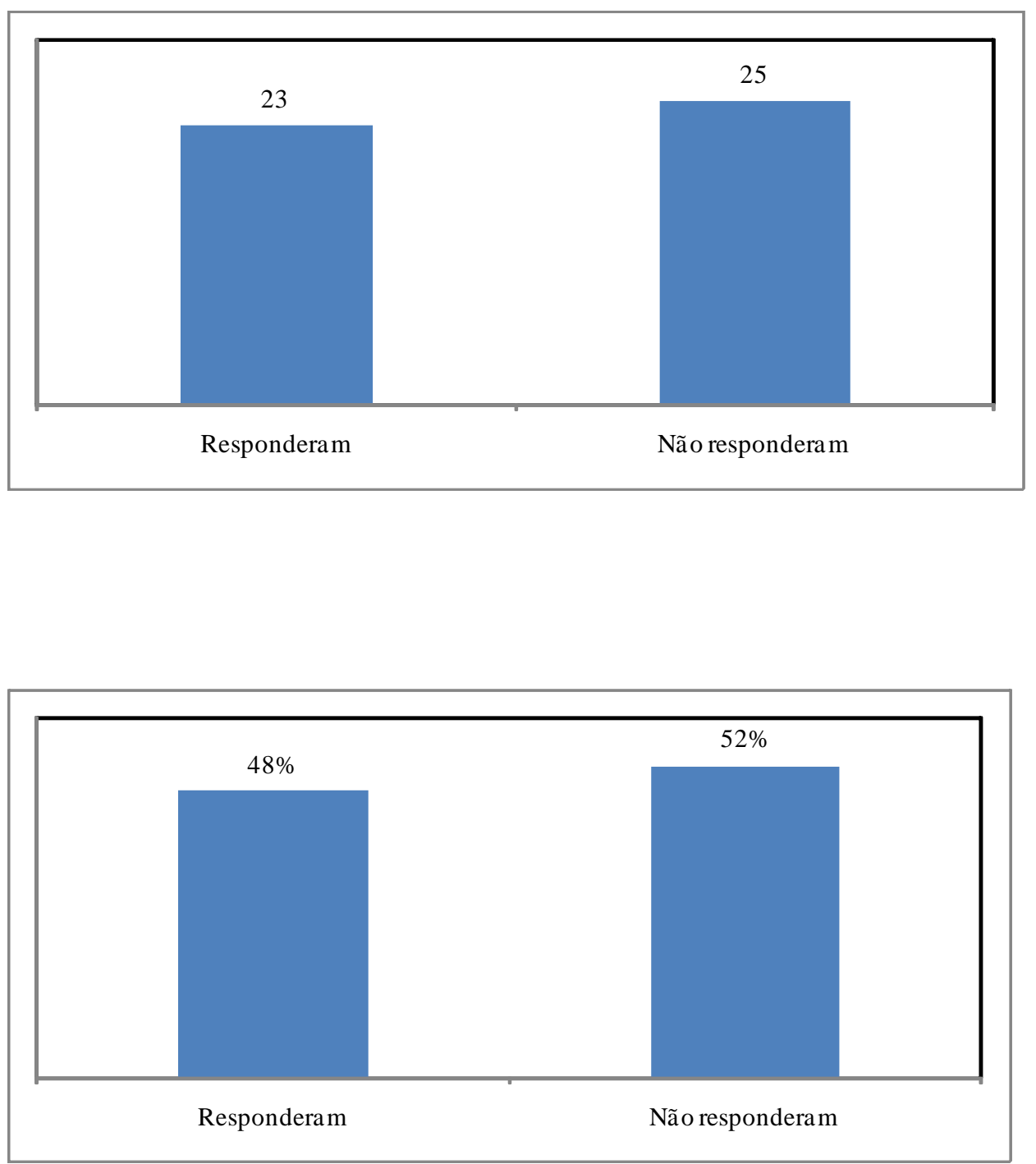


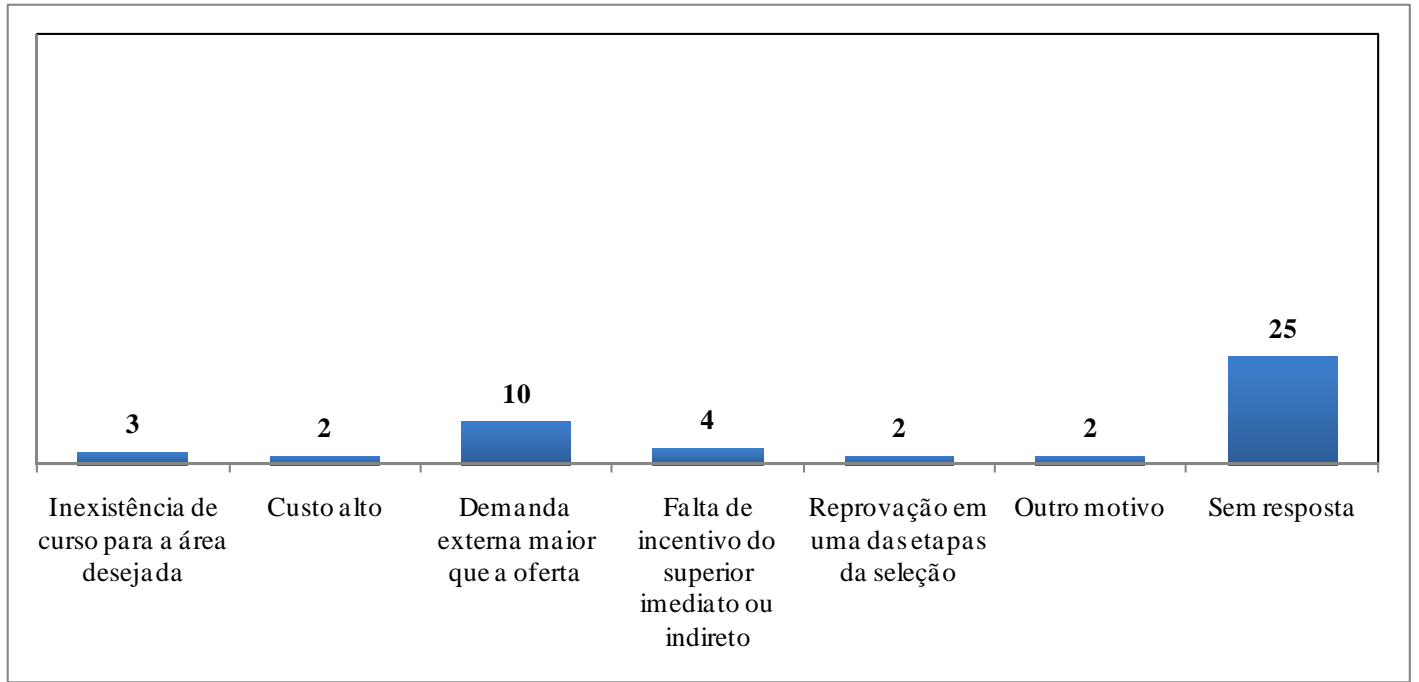

\section{Percentual}

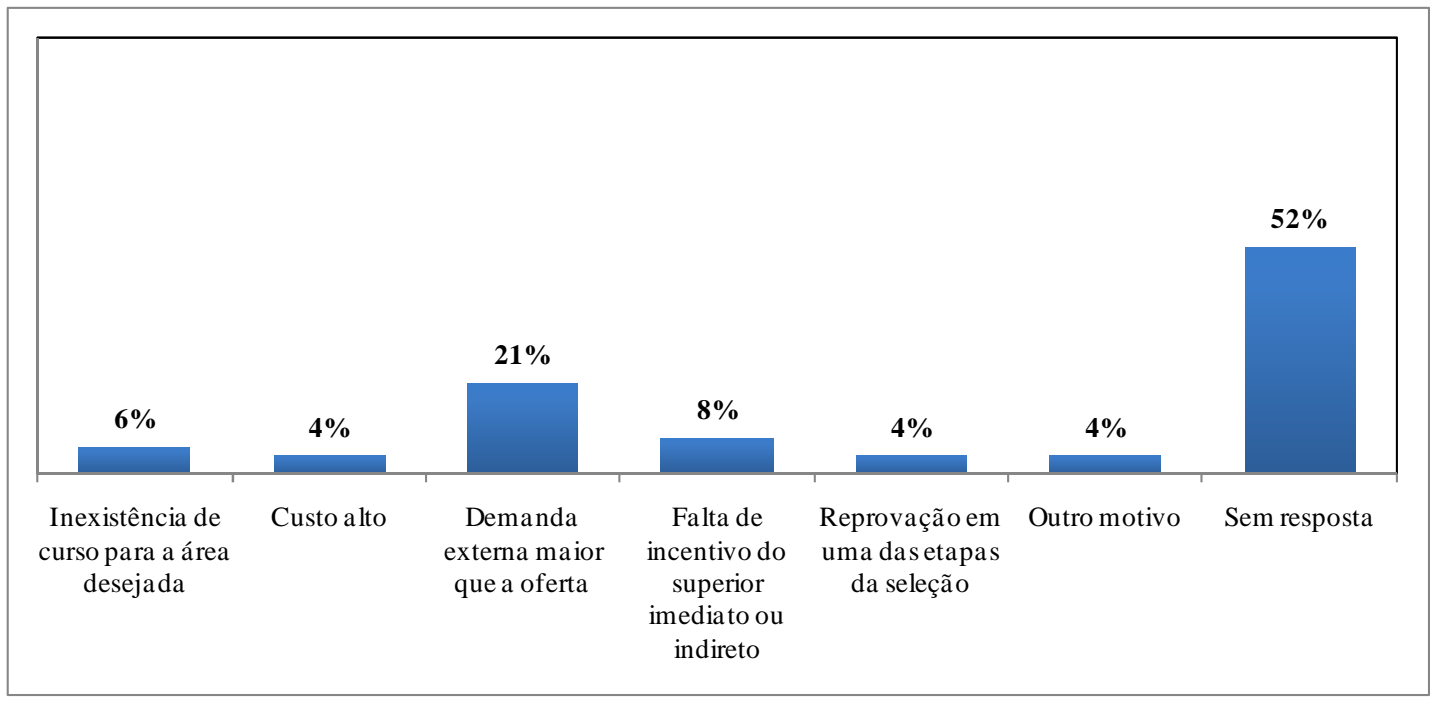

\section{Comentário:}

Os gráficos acima permitem dizer que $52 \%$ dos entrevistados não tiveram interesse em se inscrever em algum mestrado profissionalizante da UnB ou tiveram alguma tentativa fracassada. Dado relevante quando avaliado juntamente ao resultado da questão 3. Como resposta de maior recorrência, aparece a demanda externa maior que a oferta, o que reforça muito o que já foi dito no presente trabalho. 
Questão 7: Caso você tenha sinalizado algum motivo na questão n. 6, indique abaixo o que você pretende fazer em relação ao mestrado profissionalizante.

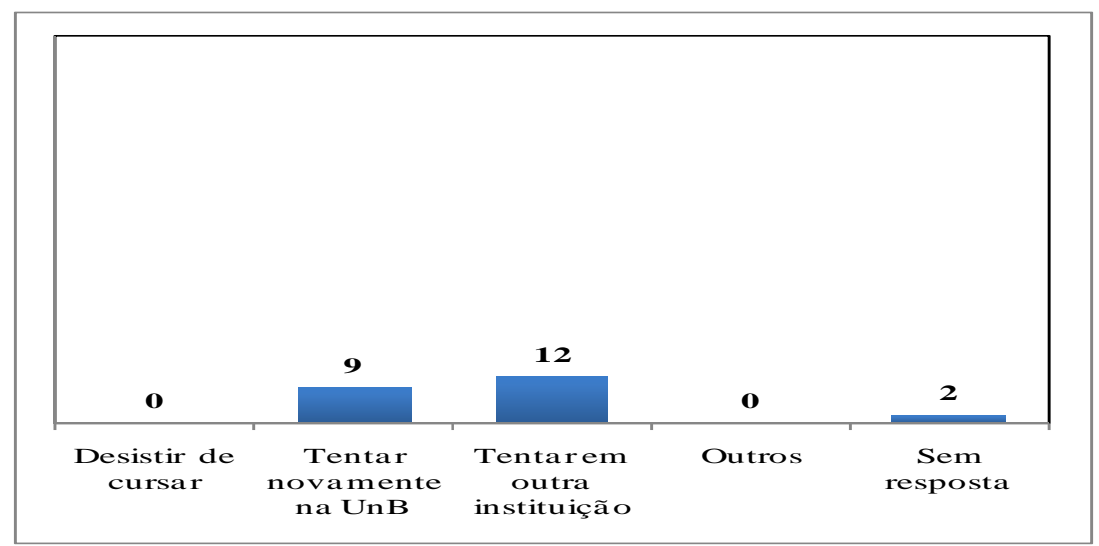

Percentual

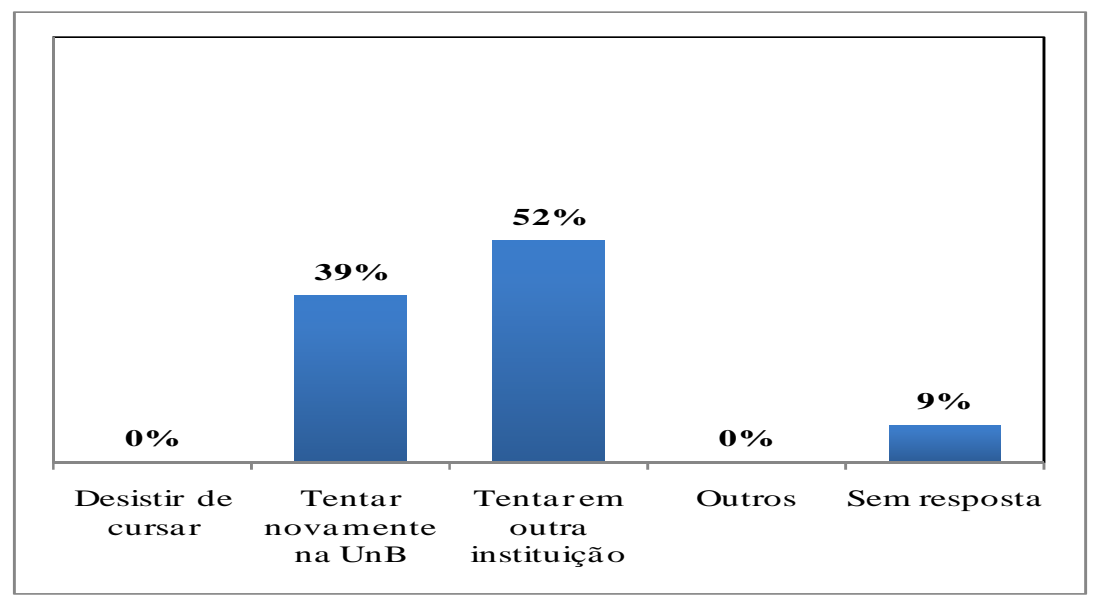

Comentário:

Daqueles que responderam à questão 7, que foram poucos, $52 \%$ pretendem tentar o mestrado profissionalizante em outra instituição e $39 \%$, novamente na UnB. Esta análise revela que a maioria dos servidores acaba desistindo de lutar para alcançar o benefício referente à titulação, procurando atingir apenas o objetivo da progressão salarial por meio de outra instituição. 


\section{CONCLUSÃO}

Em relação à formação stricto sensu, no que se refere ao mestrado profissionalizante destinado aos técnicos administrativos em educação da Universidade de Brasília, chega-se à conclusão de que essa é uma ação proveitosa e gratificante. A conclusão de um curso como esse traria muitas vantagens, tais como a melhoria considerável do nível técnico desses servidores. O que seria algo importante para a própria instituição.

Considerando a análise de dados viabilizada pelos gráficos publicados no presente trabalho, oriundos da aplicação de questionário junto aos técnicos administrativos em educação da Universidade de Brasília, é possível crer e concluir que esse público tem grande interesse no ingresso à formação stricto sensu, se oferecido pela UnB. E, principalmente, se o ingresso tiver como requisito a participação de entrevista, a título de exemplo da especialização oferecida aos servidores pela FACE, eliminando a possibilidade de concorrência entre a demanda externa.

Drucker (1999), o grande teórico das organizações modernas, na sua vasta obra, já a algumas décadas, mostrava a importância da questão do desenvolvimento humano e do processo permanente de aprendizagem e desempenho em serviço. Sua posição a respeito era a de que toda e qualquer organização deveria ser ou vir a se tornar, de fato, uma "organização de ensino”, o que a Universidade de Brasília é capaz de ser diariamente para a sociedade, e pode vir a ser para os seus servidores.

Diante do exposto, foi identificado no presente estudo que todos os objetivos foram totalmente atingidos. E nada ainda mais memorável e que pode contribuir perfeitamente para a reflexão e fechamento deste trabalho do que a própria missão da Universidade de Brasília: "Produzir, integrar e divulgar conhecimento, 
formando cidadãos comprometidos com a ética, a responsabilidade social e o desenvolvimento sustentável." 


\section{REFERÊNCIAS}

BRASIL. Decreto n. 5.824, de 29 de junho de 2006. . Lei n. 8.112, de 11 de dezembro de 1991. Lei n. 11.091, de 12 de janeiro de 2005. . Medida Provisória n. 440, de 29 de agosto de 2008. Medida Provisória n. 441, de 29 de agosto de 2008.

CASTRO, M. R. Pedro; ANDRADE, E.B. Jairo. Identificação das necessidades de capacitação profissional: o caso dos assistentes administrativos da Universidade de Brasília. Brasília, 2003.

DRUCKER, P. Desafios gerenciais para o século XXI. Editora Thomson Learning, 1999.

ANDER-EGG, E. A. Introdução às técnicas de investigação social: para trabalhadores sociais. $7^{\text {a }}$ edição, Buenos Aires: Humanistas, 1978.

MARCONI, M Andrade M; LAKATOS, Maria E. Técnicas de pesquisa. São Paulo: Atlas, 2002, p.16-40.

SPECTOR, P. Psicologia nas Organizações. Editora Saraiva. 2003.

Sistema de Informações Acadêmicas de Pós-Graduação - SIPPOS (Extrator de dados SPL) e Anuário Estatístico 2006 da Universidade de Brasília.

UNIVERSIDADE DE BRASÍLIA. Incentivo à qualificação. Disponível em <http://www.unb.br/servidor/incentivo_a_qualificacao>. Acesso em 30 de maio de 2010.

Plano de Desenvolvimento dos Integrantes do Plano de Carreira dos Cargos Técnicos Administrativos em Educação da Universidade de Brasília (PDIC/UnB). Disponível em: < http://www.srh.unb.br/>. 


\title{
Apêndice
}

\section{Questionário aplicado aos Técnicos Administrativos em Educação da Universidade}

\section{de Brasília}

\author{
1) Qual a sua idade? \\ 2) Qual o seu grau de instrução? \\ 3) Você tem interesse em cursar algum mestrado profissionalizante oferecido pela Universidade de
} Brasília?
( ) SIM
( ) NÃO

4) Você já cursou algum mestrado profissionalizante que não tenha sido oferecido pela Universidade de Brasília?
( ) SIM
( ) NÃO

Na questão n. ${ }^{\circ}$ 3, se você optou pela resposta ( )não, agradeço pela sua contribuição, se você optou pela resposta ( ) sim, favor continuar respondendo as questões que seguem.

5) Enumere abaixo por ordem de prioridade de 1 a 4 , sendo 1 maior prioridade e 4 menor prioridade o objetivo do seu interesse para a inserção em cursos stricto sensu (profissionalizante)?

( ) progressão funcional

( ) aprimoramento intelectual

( ) investimento em uma nova carreira

( ) outro motivo

6) Houve alguma tentativa ou interesse de sua parte para se inscrever em algum curso de mestrado profissionalizante na UnB que não foi bem sucedida? ( ) sim （ ) não

Se sim, sinalize abaixo o(s) motivo(s).

( ) inexistência de curso para a área desejada

( ) custo alto

( ) demanda externa maior que a oferta (concorrência)

( ) falta de incentivo do superior direto ou indireto

( ) reprovação em uma das etapas da seleção

( ) outro motivo (

7) Caso você tenha sinalizado algum motivo na questão n. $^{\circ} 6$, indique abaixo o que você pretende fazer em relação ao mestrado profissionalizante.

( ) desistir de cursar ( ) tentar novamente na UnB （ ) tentar em outra instituição

( ) outros ( 
Anexo

De acordo com os dados publicados no sítio da UnB (www.unb.br), disponibilizado pelo Sistema de Informações Acadêmicas de Pós-Graduação - SIPPOS, extraídos pela Secretaria de Planejamento para a composição do Anuário Estatístico de 2006:

Em todos os níveis de estudo da universidade, a área que teve a maior evolução foi a pós-graduação. Entre 1993 e 2003, o número de mestrados acadêmicos e profissionalizantes e de doutorados passou de 51 para 83 - aumento de 62\%. Somente em 2003, passaram a ser oferecidas quatro novas opções de mestrado Ciências Mecânicas, Informática, Estudos Comparados sobre as Américas e Sistemas Mecatrônicos - e duas de doutorado Arquitetura, Urbanismo e Comunicação.

Entre 1999 e 2003, houve um crescimento de 39\% dos alunos registrados no mestrado e de $70 \%$ no número de títulos outorgados no mestrado. Nesse mesmo período, aumentou em $36,4 \%$ o número de cursos de doutorado, em $67,6 \%$ os alunos de doutorado e em $92,3 \%$ o número de títulos outorgados no doutorado. A tabela abaixo mostra o ingresso de alunos nos cursos de pós-graduação stricto sensu (mestrado e doutorado), desde 1999. Esse crescimento representa 500\%. No mesmo período, o número de cursos aumentou $164 \%$. O maior crescimento foi nos cursos de doutorado. De 14, em 1994, o saldo foi a 31, em 10 anos.

Além da expansão dos cursos, a pós-graduação avançou também em qualidade. De acordo com a avaliação da Coordenação de Aperfeiçoamento de Pessoal de Nível Superior (Capes) do Ministério da Educação, referente ao triênio 1998/2000, 70,59\% dos programas de pós-graduação tiveram conceitos entre quatro e sete, sendo que os que têm apenas cursos de mestrado só podem alcançar a nota cinco. Na avaliação do período 2001-2003, os resultados são ainda melhores: cerca de $85 \%$ dos programas têm conceitos entre quatro e sete, inclusive.

Outro indicativo do amadurecimento da pós-graduação da UnB é o aumento do número de incentivos (bolsas de estudo, de pesquisa e fomento à pesquisa) oferecidos pelo Conselho Nacional de Desenvolvimento Científico e Tecnológico (CNPq). A UnB saiu de $\mathrm{R} \$ 11,7$ milhões em 1999 e chegou a R\$ 15,7 milhões em 2002.

Fonte: Sistema de Informações Acadêmicas de Pós-Graduação - SIPPOS (Extrator de dados SPL) e Anuário Estatístico 2006. 